\title{
Correlação canônica entre caracteres de tubérculos para seleção precoce de clones de batata
}

\author{
Canonical correlation for tuber trait to assist early selection of potato clones
}

\author{
Maria Helena Rigão ${ }^{\mathrm{I}}$ Lindolfo Storck ${ }^{\mathrm{II} *}$ Dilson Antônio Bisognin ${ }^{\mathrm{II}}$ Sidinei José Lopes ${ }^{\mathrm{II}}$
}

\section{RESUMO}

Uma das estratégias utilizadas pelos melhoristas de batata é a eliminação de um grande número de clones nas primeiras gerações de seleção, para reduzir os custos e o trabalho de manutenção e multiplicação destes. O objetivo deste trabalho foi avaliar o uso da correlação canônica entre caracteres de tubérculos plantados, relacionados com os colhidos, para auxiliar a seleção precoce de clones de batata. Foram conduzidos três ensaios em diferentes épocas, na área experimental do Departamento de Fitotecnia da Universidade Federal de Santa Maria. Foram avaliados os tubérculossemente e aqueles colhidos de 10 progênies de batata. Os caracteres utilizados para a análise da correlação canônica foram: o comprimento, o maior e o menor diâmetro e a massa fresca. Com o uso da correlação canônica, observou-se que há relação das diferentes características dos tubérculos plantados e daqueles colhidos. O comprimento apresentou a maior associação entre os tubérculos plantados e colhidos. Tubérculos compridos resultam na produção de tubérculos alongados.

Palavras-chave: Solanum tuberosum L., melhoramento de batata, comprimento de tubérculos, diâmetro de tubérculos, análise multivariada.

\section{ABSTRACT}

A potato breeding strategy is applied in early selection to discard the majority of potato clones, to reduce costs and efforts for maintenance and multiplication. The objective of this research was to test the canonical correlation of seeded tuber traits and harvested tubers to assist the early selection of potato clones. Three experiments in different seasons were carried out in the experimental area of the Horticultural Department of the Federal University of Santa Maria. Seeded and harvested tubers of ten potato progeny were evaluated. The tuber traits length, larger and smaller diameter, and fresh weight were submitted to canonical correlation analysis. The canonical correlation showed a trait relationship between potato seeds and their production. The largest association was tuber length. Therefore, long seed tubers produce elongated tubers as well.

Key words: Solanum tuberosum L., potato breeding, tuber length, tuber diameter, multivariate analysis.

\section{INTRODUÇÃO}

Os programas brasileiros de melhoramento genético de batata são de fundamental importância, tanto na perspectiva de que esse produto tem um papel importante na nutrição humana, como uma fonte de alimento adequada, sustentável e de alta qualidade para as populações, quanto na busca de alternativas para as cultivares desenvolvidas em outros países (PEREIRA, 2003; SILVA et al., 2006). O melhoramento genético, para a obtenção de novas cultivares, é uma tarefa de longo prazo. Uma alternativa para acelerar esse processo é realizar a seleção precoce, ou seja, a seleção nas primeiras gerações após a hibridação. A vantagem da seleção precoce é poder agilizar o programa e encurtar os ciclos de seleção, desde que clones superiores da progênie possam ser adequadamente identificados nas primeiras gerações clonais. O descarte do maior número possível de clones com caracteres indesejáveis, na primeira geração clonal, também é recomendado, para reduzir os custos e o trabalho para a manutenção e multiplicação destes (BISOGNIN \& DOUCHES, 2002; BISOGNIN, 2003).

\footnotetext{
IPrograma de Pós-graduação em Agronomia, Universidade Federal de Santa Maria (UFSM), Santa Maria, RS, Brasil.

IIDepartamento de Fitotecnia, Centro de Ciências Rurais (CCR), UFSM. Av. Roraima, 1000, Campus Universitário, 97105-900, Santa Maria, RS, Brasil. E-mail: lindolfo@pq.cnpq.br. *Autor para correspondência.
} 
O desenvolvimento de novas cultivares de batata recebe, cada vez mais, contribuição das técnicas biotecnológicas, que não substituirão os programas de melhoramento tradicional, e o melhorista deve examinar criticamente a aplicação de todas as metodologias quanto aos aspectos econômicos e a eficiência das mesmas (PEREIRA, 2003). Outra importante contribuição, para se obter o progresso genético no melhoramento de plantas, é a necessidade de estabelecer critérios de seleção artificial que sejam eficientes; portanto, de análises estatísticas que venham a auxiliar na escolha da melhor estratégia de seleção, tornam-se importantes ferramentas para melhor entendimento das relações genéticas entre os caracteres (CARVALHO et al., 2001).

A análise de correlação canônica é uma técnica estatística multivariada que permite examinar a estrutura da relação existente entre dois grupos de variáveis ( $\mathrm{X}$ e $\mathrm{Y}$ ), isto é, mede a existência e a intensidade de associação entre os grupos, compostos por combinações lineares dos vários caracteres que os constituem. A equação básica é expressa por: $X_{1}+X_{2}$ $+\mathrm{X}_{3}+\ldots+\mathrm{X}_{\mathrm{p}}=\mathrm{Y}_{1}+\mathrm{Y}_{2}+\mathrm{Y}_{3}+\ldots+\mathrm{Y}_{\mathrm{q}}$. O princípio da correlação canônica é desenvolver uma combinação linear, em cada um dos conjuntos de variáveis (X e Y), de modo que a associação seja maximizada. Nesse método, não existe distinção entre variável independente e dependente, existem somente dois conjuntos de variáveis, em que se busca a máxima correlação entre ambos (MORRISON, 1978).

O objetivo deste trabalho foi avaliar o uso da correlação canônica para a identificação de caracteres de tubérculos plantados, relacionados com os colhidos, para auxiliar a seleção precoce de clones de batata.

\section{MATERIAL E MÉTODOS}

Três experimentos, em épocas distintas de cultivo, foram realizados no campo experimental do Departamento de Fitotecnia da Universidade Federal de Santa Maria (UFSM), Santa Maria, Rio Grande do Sul (RS). Aépoca 1 foi realizada em latitude 2943' 28"S, longitude 53\%43'11"W e 102m de altitude, a época 2, em latitude $29^{\circ} 43^{\prime} 29^{\prime \prime S}$, longitude 53\%43'17"W e 105m de altitude, e a época 3, em latitude $29^{\circ} 43^{\prime} 35^{\prime \prime S}$, longitude $53^{\circ} 43^{\prime} 18^{\prime \prime} \mathrm{W}$ e $107 \mathrm{~m}$ de altitude. O solo pertence à unidade de mapeamento Santa Maria e é classificado como Brunizem Hidromórfico pelo Sistema de Brasileiro de Classificação de Solos (EMBRAPA, 1999). O clima da região, segundo a classificação de Köeppen (MORENO, 1961), é do tipo Cfa - temperado chuvoso, com chuvas bem distribuídas ao longo do ano e subtropical do ponto de vista térmico.
Foram utilizados 100 tubérculos (clones) oriundos de 10 progênies desenvolvidas no Programa de Genética e Melhoramento de Batata da UFSM. As progênies foram: A504 (Michigan Purple x SMIJ319-1) (três clones); A508 (Asterix x SMIJ456-4Y) (17 clones); A509 (SMIG274-3 x A091-1) (10 clones); A511 (H101-2 x SMIG274-3) (11 clones); A514(E226-5 x SMIG274-3) (10 clones); A517 (Torridon x BI865-2) (10 clones); A518 (Torridon x B0288-17) (11 clones); A519 (H054-3 x Tollocan) (oito clones); A520 (Stirling x MSH419-1) (dez clones); e A701 (Monalisa x Ciclaman) (10 clones).

Os tubérculos-semente foram separados e tratados para a quebra de dormência com 30ppm de ácido giberélico (BENEDETTI et al., 2005) e armazenados a $25^{\circ} \mathrm{C}$, até o plantio. Previamente ao plantio de cada experimento, os tubérculos-semente foram avaliados quanto: ao comprimento, ao maior e ao menor diâmetro e à massa fresca. Para os três experimentos, foi utilizado o delineamento inteiramente casualizado. Em cada cova, foi plantado um tubérculosemente, devidamente identificado, formando fileiras separadas de $0,80 \mathrm{~m}$ e as covas de $0,33 \mathrm{~m}$. O manejo da cultura, incluindo preparo do solo, adubação, tratos culturais e colheita, foi realizado segundo as recomendações técnicas de BISOGNIN (1996). Os tubérculos colhidos em cada cova, correspondentes ao respectivo tubérculo-semente, foram avaliados para os mesmos caracteres do tubérculo-semente, com estimação das médias entre os tubérculos de cada cova: comprimento, maior diâmetro, menor diâmetro e massa fresca. Os dados dos tubérculos-semente formaram o primeiro grupo de caracteres (G1), e as médias dos tubérculos colhidos em cada cova, o segundo grupo de caracteres (G2). Os grupos de caracteres (G1 e G2) foram utilizados para a realização da análise de correlação canônica para cada um dos experimentos.

No primeiro experimento ou na primeira época correspondente à primeira geração de seleção, foram plantados, no dia 14 de março de 2006, os tubérculos de 100 clones, sendo um tubérculo-semente em cada cova. A colheita foi realizada em 15 de junho de 2006, obtendo-se um total de 261 tubérculos nas 71 covas, com produção. Foram separados, quando possível, três tubérculos de cada cova de tamanho grande, pequeno e intermediário, que foram os tubérculos-semente da próxima geração ou do segundo experimento.

Os dados das avaliações dos tubérculossemente (antes do plantio) (G1) e as médias dos respectivos tubérculos colhidos (G2) foram submetidos às análises das medidas descritivas de ambos os grupos (G1 e G2). Também foram realizados a análise da 
correlação de Pearson (dentro de G1 e G2 e entre G1 e $\mathrm{G} 2$ ), para verificar a linearidade entre os caracters, e o estudo da multicolinearidade dentro de cada grupo, visando a reduzir o efeito perturbador da colinearidade na estimativa da correlação canônica. Em seguida, foram realizadas a análise de variância para cada um dos caracteres e a análise de correlação canônica entre os grupos G1 e G2.

Para o cálculo da correlação canônica, denotaram-se as medidas dos tubérculos plantados (variáveis do G1) como X (x1, x2, x3, x4) e as medidas dos tubérculos colhidos (variáveis do G2) como Y (y1, $\mathrm{y} 2, \mathrm{y} 3, \mathrm{y} 4) . \mathrm{O} \mathrm{X}^{\prime}=\left[\mathrm{x}_{1} \mathrm{x}_{2} \ldots \mathrm{x}_{\mathrm{p}}\right]$ é o vetor das medidas das p características do grupo 1 , e o $\mathrm{Y}^{\prime}=\left[\begin{array}{ll}\mathrm{y}_{1} & \mathrm{y}_{2} \ldots \mathrm{y}_{\mathrm{q}}\end{array}\right]$ é o vetor das medidas das q características do grupo 2 . Das combinações lineares $\mathrm{X}_{1}=\mathrm{a}_{1} \mathrm{X}_{1}+\ldots+\mathrm{a}_{\mathrm{p}} \mathrm{x}_{\mathrm{p}}$ e $\mathrm{Y}_{1}=$ $\mathrm{b}_{1} \mathrm{y}_{1}+\ldots+\mathrm{b}_{\mathrm{q}} \mathrm{y}_{\mathrm{p}}$ os valores $\mathrm{a}{ }^{\prime}=\left[\mathrm{a}_{1} \ldots \mathrm{a}_{\mathrm{p}}\right]$ e b' $\stackrel{\mathrm{p}}{=}\left[\mathrm{b}_{1} \ldots \mathrm{b}_{\mathrm{q}}\right]$ são os vetores dos pesos das características correspondentes aos grupos 1 e 2 , respectivamente. A

primeira correlação canônica, $r_{1}=\frac{\operatorname{cov}\left(X_{1}, Y_{1}\right)}{\sqrt{\operatorname{var}\left(X_{1}\right) \operatorname{var}\left(Y_{1}\right)}}$, é a

que maximiza a relação entre as funções $X_{1}$ e $Y_{1}$, que representam o primeiro par canônico, sendo: $\operatorname{cov}\left(\mathrm{X}_{1}\right.$, $\left.\mathrm{Y}_{1}\right)=\mathrm{a}^{\prime} \mathrm{S}_{12} \mathrm{~b} ; \operatorname{var}\left(\mathrm{X}_{1}\right)=\mathrm{a}^{\prime} \mathrm{S}_{11} \mathrm{a} ; \operatorname{var}\left(\mathrm{Y}_{1}\right)=\mathrm{b}^{\prime} \mathrm{S}_{22} \mathrm{~b} ; \mathrm{S}_{11}=$ matriz pxp de covariâncias dos caracteres do grupo 1; $\mathrm{S}_{22}=$ matriz qxq de covariâncias dos caracteres do grupo 2; $\mathrm{S}_{12}=$ matriz pxq de covariâncias entre os caracteres dos grupos 1 e 2. Quando são utilizadas variáveis padronizadas, substituem-se as matrizes de covariâncias pelas matrizes das correlações. Sendo $\mathrm{R}_{11}$, $\mathrm{R}_{22}$ e $\mathrm{R}_{12}$ as matrizes das correlações amostrais, a primeira correlação canônica (r1), correspondente ao primeiro par canônico, é a raiz quadrada o primeiro autovalor ( $\mathrm{r} 1=\sqrt{\lambda_{1}}$ ), solução da equação $\mid \mathrm{R}_{11} \mathrm{R}_{22}{ }^{-1} \mathrm{R}_{12}{ }^{-}$ $\lambda R_{11} \mid$. De modo análogo, encontram-se as demais correlações canônicas. Os coeficientes de ponderação dos pares canônicos são os autovetores associados aos respectivos autovalores. O teste de significância para todas as correlações canônicas é: $H_{0}: \rho_{1}=\rho_{2}=\ldots$ $=\rho_{\mathrm{s}}=0, \mathrm{~s}=\min \{\mathrm{p}, \mathrm{q}\} ; \mathrm{H}_{1}: \rho_{\mathrm{i}} \neq 0$ para algum $\mathrm{i} ; 1 \leq \mathrm{i} \leq \mathrm{s}$. A estatística do teste é: $\chi^{2}=-[\mathrm{n}-0,5(\mathrm{p}+\mathrm{q}+3)] \ln \left[\prod_{1}^{s}\left(1-r_{i}^{2}\right)\right]$, que segue a distribuição $\chi_{(\alpha ; p)}^{2}$. Nessa expressão, $\mathrm{n}=$ número de observações; $\mathrm{p}=$ =número de variáveis do grupo $\mathrm{X}$; q=número de variáveis do grupo $\mathrm{Y}$; $r_{i}^{2}=$ correlação canônica, ao quadrado, da equação a ser testada. Se a hipótese é rejeitada, faz-se o teste: $\mathrm{H}_{\mathrm{o}}: \rho_{\mathrm{k}}>0$ e $\rho_{\mathrm{k}+1}=\rho_{\mathrm{k}+2}=\ldots=\rho_{\mathrm{s}}=0, \mathrm{~s}=\min \{\mathrm{p}, \mathrm{q}\}$ por meio de $\chi^{2}=-[n-0,5(\mathrm{p}+\mathrm{q}+3)] \ln \left[\prod_{i=1}^{\mathrm{s}}\left(1-r_{i}^{2}\right)\right]$, que segue a distribuição $\chi_{[\alpha ;(\mathrm{p}-\mathrm{k})(\mathrm{q}-\mathrm{k})]}^{2}($ CRUZ \& REGAZZI, 1994).

No dia 25 de agosto de 2006 (segunda época ou experimento), foram plantados 161 tubérculos, obtidos da produção do primeiro experimento, cuja colheita foi realizada no dia 06 de dezembro de 2006. Foram avaliados os mesmos caracteres, tanto nos tubérculos plantados, quanto naqueles colhidos em cada cova. Também foram realizadas as mesmas análises estatísticas descritas para o primeiro experimento.

No dia 15 de março de 2007 (terceira época ou experimento), foram plantados 59 tubérculos, obtidos da produção do segundo experimento, cuja colheita foi realizada no dia 04 de junho de 2007. Foram avaliados os mesmos caracteres, tanto nos tubérculos plantados, quanto naqueles colhidos em cada cova. Também foram realizadas as mesmas análises estatísticas descritas para o primeiro experimento.

As análises estatísticas foram realizadas com os aplicativos computacionais Genes (CRUZ, 2001) e SAEG (2007).

\section{RESULTADOS E DISCUSSÃO}

As médias das medidas dos caracteres dos tubérculos-semente (G1) e dos colhidos (G2) foram maiores no G2 na primeira época, menores no G2 da segunda época e semelhantes na terceira época (Tabela 1). Os valores dos coeficientes de variação (CV\%) da massa fresca dos tubérculos plantados e colhidos são os maiores e semelhantes nas três épocas. Os CV\% dos caracteres dimensionais (comprimento, maior e menor diâmetro) foram sensivelmente menores entre os tubérculos colhidos (na segunda e na terceira época) em comparação com os tubérculos plantados. Manter a variabilidade dentro de progênies nas três épocas foi proposital, pois se escolheu trabalhar com tubérculos de maior amplitude de dimensões, importante para melhorar as estimativas das correlações lineares entre os caracteres e da correlação canônica. A variabilidade entre as progênies foi significativa no plantio e na colheita da primeira época e na colheita de terceira época (Tabela 1), fato que mostra a variabilidade entre os clones.

Na segunda época, as médias de todos os caracteres dos tubérculos do G2 diminuíram em relação aos mesmos caracteres do G1, e a massa fresca de tubérculos passou de 72,73g para 25,05g nos tubérculos colhidos, possivelmente, como consequência do excesso de chuvas no período. No período de 60 dias após o plantio, ocorreu um total de $364 \mathrm{~mm}$ de precipitação, período em que qualquer estresse afeta o rendimento final (PEREIRA \& DANIELS, 2003). Aliado a isso, o rendimento também é afetado pela menor radiação solar que, conforme BISOGNIN et al. (2008), é a variável ambiental determinante das diferenças de rendimento nas condições de cultivo de primavera e outono nessa região. Também contribuiu para a baixa 
Tabela 1 - Médias e coeficientes de variação (CV\%) dos caracteres correspondentes aos tubérculos plantados e colhidos nas três épocas (n = número de covas).

\begin{tabular}{|c|c|c|c|c|c|}
\hline \multirow{2}{*}{ Caracteres avaliados } & \multirow[b]{2}{*}{$\mathrm{n}$} & \multicolumn{2}{|c|}{ Tubérculos plantados (G1) } & \multicolumn{2}{|c|}{ Tubérculos colhidos (G2) } \\
\hline & & Média & $\mathrm{CV} \%$ & Média & $\mathrm{CV} \%$ \\
\hline & \multicolumn{5}{|c|}{ 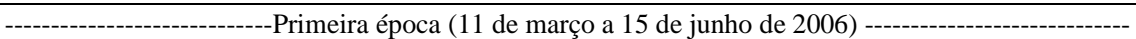 } \\
\hline Comprimento (mm) & 71 & $36,07 *$ & 32,16 & $48,73^{\text {ns }}$ & 31,03 \\
\hline Maior diâmetro (mm) & 71 & $27,41^{*}$ & 28,99 & $38,57 *$ & 30,72 \\
\hline Menor diâmetro (mm) & 71 & $23,72 *$ & 26,77 & $32,63 *$ & 27,63 \\
\hline \multirow[t]{2}{*}{ Massa fresca (g) } & 71 & $17,01^{*}$ & 82,17 & $51,22 *$ & 80,34 \\
\hline & \multicolumn{5}{|c|}{---Segunda época (25 de agosto a 6 de dezembro de 2006) - } \\
\hline Comprimento (mm) & 85 & $56,07^{\mathrm{ns}}$ & 35,99 & $42,39 *$ & 25,53 \\
\hline Maior diâmetro (mm) & 85 & $45,17^{\mathrm{ns}}$ & 32,94 & $30,34^{\mathrm{ns}}$ & 21,28 \\
\hline Menor diâmetro (mm) & 85 & $37,89^{\text {ns }}$ & 30,01 & $26,18^{\text {ns }}$ & 20,57 \\
\hline \multirow[t]{2}{*}{ Massa fresca (g) } & 85 & $72,73^{\mathrm{ns}}$ & 85,43 & $25,05^{\mathrm{ns}}$ & 61,46 \\
\hline & \multicolumn{5}{|c|}{---------------------Terceira época (15 de março a 4 de junho de 2007) - } \\
\hline Comprimento (mm) & 53 & $48,03^{\text {ns }}$ & 37,88 & $47,92 *$ & 23,96 \\
\hline Maior diâmetro (mm) & 53 & $34,56^{\mathrm{ns}}$ & 25,21 & $37,06^{*}$ & 22,14 \\
\hline Menor diâmetro (mm) & 53 & $30,02^{\mathrm{ns}}$ & 24,15 & $31,53^{*}$ & 20,82 \\
\hline Massa fresca (g) & 53 & $34,59^{\text {ns }}$ & 81,31 & $39,57 *$ & 61,75 \\
\hline
\end{tabular}

* As médias de progênies são diferentes dentro do grupo, pelo teste F, $\alpha=5 \%$; ns = diferenças não significativas.

massa fresca por tubérculo o fato de que um terço dos tubérculos selecionados para o plantio apresentava tamanho relativamente menor, visando a manter a variabilidade. Já na terceira época, por se tratar da terceira geração clonal, esperavam-se valores maiores dos caracteres avaliados na colheita. No entanto, devido às medidas menores dos tubérculos plantados (os mesmos colhidos na época 2) e, também, devido às condições ambientais não favoráveis, as médias das medidas foram semelhantes.

Na primeira e na terceira época, em que a média da massa fresca de tubérculos colhidos foi maior devido às condições ambientais mais favoráveis, observou-se diferença significativa entre os clones para a maioria dos caracteres. Devido ao fato da heterogeneidade (valores altos dos CV\%) entre os tubérculos plantados e colhidos, podem-se estimar os coeficientes de correlação com a devida representatividade da associação entre os caracteres, pois a falta de variação em uma das variáveis causa indeterminação nas estimativas da correlação.

As correlações lineares entre os caracteres do G1 e entre os caracteres do G2 (Tabela 2), nas três épocas, foram significativas, positivas e altas. Nas três épocas e nos dois grupos (plantado e colhido), a multicolineridade foi relativamente fraca (número de condição menor que 140), permitindo que todos os caracteres fossem usados para a realização da análise de correlação canônica, pois, quando variáveis estão correlacionadas entre si, deve-se considerar que o efeito da colinearidade pode levar a resultados pouco confiáveis, induzindo conclusões equivocadas na correlação canônica (CRUZ \& CARNEIRO, 2003). Comparando as correlações significativas entre os caracteres dos tubérculos do G1 e do G2, observa-se que essas relações manifestaram-se de modo distinto. Na época 1, apenas o maior diâmetro, o menor diâmetro e a massa fresca tiveram correlação linear significativa e somente com o caractere menor diâmetro, ou seja, apenas três correlações significativas. Já na época 2, ocorreram 14 correlações significativas: comprimento, maior e menor diâmetro tiveram correlação significativa, com todos os caracteres correspondentes aos tubérculos colhidos. Porém, na época 3, a relação é completamente distinta, apenas maior diâmetro e menor diâmetro foram significativos com todos os caracteres dos tubérculos colhidos (Tabela 2). Essas diferenças reafirmam os resultados de muitos trabalhos (LOVATO, 1993; MENEZES et al., 1999; LAMBERT, 2004; ANDREU, 2005; BISOGNIN et al., 2008), mostrando que fatores ambientais afetam não só a produção, mas também a aparência e a qualidade de tubérculos.

Quanto às correlações canônicas das três épocas (uma sequência de três gerações clonais), podese observar que, na segunda época, o valor da correlação significativa foi o mais baixo (r1=0,4968), enquanto que, na época 1 (r1=0,6782) e na época 3 ( $\mathrm{r} 1=0,6420)$, foram maiores e muito próximos (Tabela 3).

$\mathrm{Na}$ primeira época, os coeficientes canônicos indicam a associação entre comprimento e 
Tabela 2 - Correlação linear entre os caracteres dos tubérculos de clones de batata plantados (x) e colhidos (y) em três épocas.

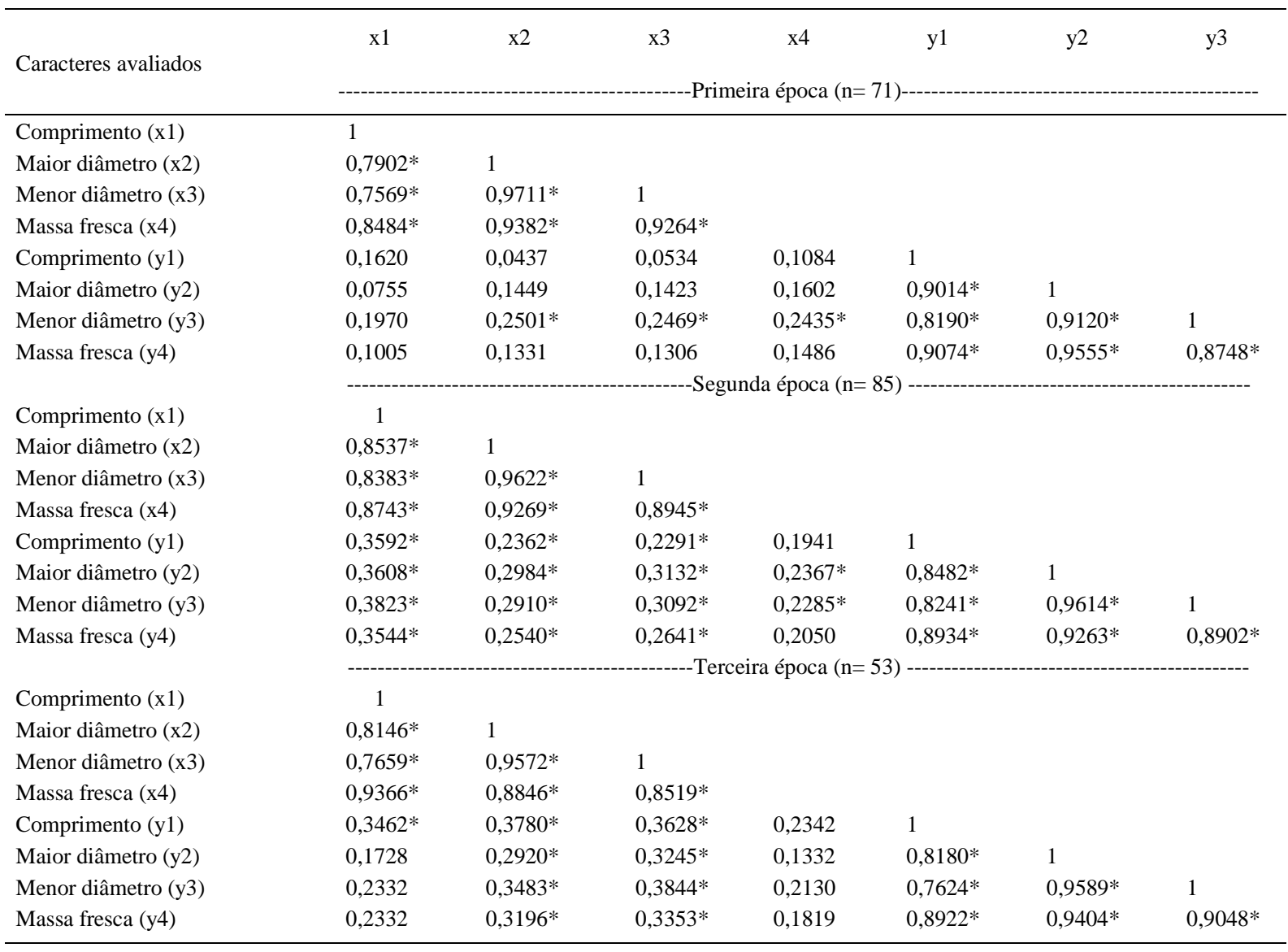

* Significativo pelo teste t, em nível de 5\% de probabilidade de erro.

maior diâmetro, sugerindo uma relação inversa, ou seja, tubérculos mais compridos e com maior diâmetro de menor magnitude produziram tubérculos de formato semelhante. Os outros coeficientes, por serem bem menores, pouco contribuíram para essa associação. Essa foi a época em que houve o menor número de correlações lineares significativas entre G1 e G2, três de um total de 16 (Tabela 2).

Tabela 3 - Coeficientes canônicos e correlação canônica do primeiro par, para caracteres de tubérculos de batata plantados e colhidos, nas três épocas de cultivo.

\begin{tabular}{|c|c|c|c|}
\hline \multirow{2}{*}{ Caracteres avaliados } & \multicolumn{3}{|c|}{-Épocas de cultivo- } \\
\hline & Primeira & Segunda & Terceira \\
\hline & \multicolumn{3}{|c|}{ 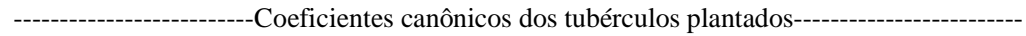 } \\
\hline Comprimento (x1) & $-0,5060$ & 0,7698 & 0,9753 \\
\hline Maior diâmetro (x2) & 0,6577 & 0,1017 & 0,4784 \\
\hline Menor diâmetro (x3) & $-0,3087$ & 0,0103 & 0,1065 \\
\hline Massa fresca $(x 4)$ & 0,1312 & $-0,6264$ & $-1,2240$ \\
\hline Comprimento (y1) & $-0,7029$ & $\begin{array}{c}\text { nicos dos } \mathrm{t} \\
0,2351\end{array}$ & 0,7939 \\
\hline Maior diâmetro (y2) & 0,6971 & $-0,6649$ & $-0,1425$ \\
\hline Menor diâmetro (y3) & $-0,1087$ & 0,6962 & 0,2758 \\
\hline Massa fresca $(\mathrm{y} 4)$ & 0,0901 & 0,1337 & $-0,5227$ \\
\hline Correlação canônica (r1) & 0,6782 & 0,4968 & 0,6420 \\
\hline
\end{tabular}

Ciência Rural, v.39, n.8, nov, 2009. 
Os coeficientes canônicos (Tabela 3) não mostram com clareza e coerência as relações entre tubérculos plantados e colhidos na segunda época. Também nessa época ocorreu o maior número de correlações lineares significativas entre G1 e G2 (Tabela 2), e as dimensões dos caracteres observados nos tubérculos foram fortemente afetadas pelo ambiente de cultivo (Tabela 1 ).

Por fim, na terceira e na última época, os coeficientes canônicos mostram claramente a relação entre os caracteres, embora não sejam os mesmos da primeira época. Aqui, observa-se a relação inversa entre comprimento e massa fresca, indicando que tubérculos longos e de menor massa produziram, também, tubérculos longos e de menor massa. Os outros coeficientes contribuíram pouco para a interpretação, por serem bem menores. Nessa época, apenas nove das 16 correlações lineares entre G1 e G2 foram significativas (Tabelas 2).

Embora não tenha sido observada uma coerência entre os resultados da análise de correlação canônica obtidos nas três épocas (sequência de três gerações clonais), o fato de haver significância estatística, para o primeiro par canônico (nas três épocas), indica que existe relação entre as medidas dos caracteres de tubérculos plantados com a respectiva produção. Na prática, esse fato pode auxiliar o processo de melhoramento (seleção precoce pelos caracteres dos tubérculos-semente). A repetição do estudo com outros materiais genéticos e/ou em ambientes é recomendada para elucidar e ampliar a compreensão da relação, mesmo porque na literatura pesquisada não foram encontrados trabalhos utilizando a correlação canônica em batata.

\section{CONCLUSÕES}

A análise de correlação canônica mostrou que existe uma associação entre as medidas dos caracteres de tubérculos plantados e colhidos no estudo das três primeiras gerações clonais de batata. A maior associação ocorreu entre comprimento, sugerindo que o plantio de tubérculos compridos resulta na produção de tubérculos alongados.

\section{AGRADECIMENTO}

Ao Conselho Nacional de Desenvolvimento Científico e Tecnológico (CNPq), pela concessão de bolsas e recursos financeiros.

\section{REFERÊNCIAS}

ANDREU, A.A. Associação entre características agronômicas da batata nos plantios de primavera e outono no Rio Grande do Sul. Ciência e Agrotecnologia, v.29, n.5, p.925-929, 2005. Disponível em: <http://www.scielo.br/scielo.php?script=sci_arttext\&pid=S1413$70542005000500001 \& \operatorname{lng}=$ en \&nrm=iso\&tlng=pt>. Acesso em: 29 jun. 2009.

BENEDETTI, M. et al. Quebra de dormência de minitubérculos de batata. Ciência Rural. v.35, n.1, p.31-38, 2005. Disponível em: $<$ http://www.scielo.br/scielo.php?pid=S 0103 84782005000100006\&script=sci_arttext\&tlng=es>. Acesso em: 29 jun. 2009. doi: 10.1590/S0103-84782005000100006.

BISOGNIN, D.A. (Coord). Recomendações técnicas para o cultivo da batata no Rio Grande do Sul e Santa Catarina. Santa Maria: Universidade Federal de Santa Maria. 1996. 64p.

BISOGNIN, D.A.; DOUCHES, D.S. Early generation selection for potato tuber quality in progenies of lateblight resistant parents. Euphytica, v.127, p.1-9, 2002. Disponível em: <http:/ /www.springerlink.com/content/w38x122n72025v03/ ?p=de4a8d81cef842fbb4fe786f96d03bda\&pi=0>. Acesso em: 29 jun. 2009. doi: 10.1023/A:1019983503697.

BISOGNIN, D.A. Melhoramento da batata para resistência às doenças. In: PEREIRA, A.S.; DANIELS, J. O cultivo da batata na região sul do Brasil. Brasília, DF: Embrapa Clima Temperado, Embrapa Informação Tecnológica, 2003. 563p.

BISOGNIN, D.A. et al. Desenvolvimento e rendimento de clones de batata na primavera e no outono. Pesquisa Agropecuária Brasileira, v.43, n.6, p.699-705, 2008. Disponível em: <http://www.scielo.br/scielo.php?pid=S0100204X2008000600005\&script=sci_arttext\&tlng=en $>$. Acesso em: 29 jun. 2009. doi: 10.1590/S0100-204X2008000600005.

CARVALHO, F.I.F. et al. Estimativas e implicações da herdabilidade como estratégia de seleção. Pelotas: UFPel, 2001. 99p.

CRUZ, C.D.; REGAZZI, A.J. Modelos biométricos aplicados ao melhoramento genético. Viçosa: UFV, 1994. 390p.

CRUZ, C.D. Programa genes: versão Windows - Aplicativo computacional em genética e estatística. Viçosa: UFV, 2001. 648p.

CRUZ, C.D.; CARNEIRO, P.C.S. Modelos biométricos aplicados ao melhoramento genético. Viçosa: UFV, 2003. V.2, 585p.

EMBRAPA - Centro Nacional de Pesquisa de Solos (Rio de Janeiro, RJ). Sistema Brasileiro de classificação de solos. Brasília: Embrapa - SPI, 1999. 412p.

LAMBERT, E.S. Estratégias para o melhoramento da batata para condições tropicais. 2004. 142f. Tese (Doutorado em Genética e Melhoramento de Plantas) Universidade Federal de Lavras, Lavras, MG.

LOVATO, C. Influência do ambiente no desenvolvimento da batata. Ciência Rural, v.23, n.1, p.101-106, 1993. 
MENEZES, C.B. et al. Avaliação de genótipos de batata (Solanum tuberosum L.) nas safras “das águas” e de inverno no sul de Minas Gerais. Ciência e Agrotecnologia, v.23, n.4, p.776-783, 1999.

MORENO, J.A. Clima do Rio Grande do Sul. Porto Alegre: Secretaria da Agricultura, 1961. 41p.

MORRISON, D.F. Multivariate statistical methods. 2.ed. Tokyo: McGraw Hill, 1978. 415p.

PEREIRA, A.S. Desenvolvimento de cultivares nacionais de batata. Batata Show, Ano 3, n.7, p.12-13, 2003.
PEREIRA, A.S.; DANIELS, J. O cultivo da batata na região sul do Brasil. Brasília, DF: Embrapa Informações Tecnológicas, 2003. 565p.

SAEG- Sistema para Análises Estatísticas, Versão 9.1. Viçosa: Fundação Arthur Bernardes. UFV, 2007.

SILVA, E.C. et al. Produção de minitubérculos a partir de brotos de cultivares de batata em diferentes combinações de substratos. Horticultura Brasileira, v.24, n.2, p.241-244, 2006 Disponível em: <http://www.scielo.br/scielo.php?pid=S0102$05362006000200025 \&$ script $=$ sci_arttext\&tlng=pt $>$. Acesso em: 29 jun. 2009. doi: 10.1590/S0102-05362006000200025. 